\title{
Organic Nitrates and Nitrate Resistance in Diabetes: The Role of Vascular Dysfunction and Oxidative Stress with Emphasis on Antioxidant Properties of Pentaerithrityl Tetranitrate
}

\author{
Matthias Oelze, Swenja Schuhmacher, and Andreas Daiber \\ The 2nd Medical Clinic, Laboratory for Molecular Cardiology, University Medical Center, Johannes Gutenberg University of Mainz, \\ 55101 Mainz, Germany \\ Correspondence should be addressed to Andreas Daiber, daiber@uni-mainz.de
}

Received 9 September 2010; Accepted 1 November 2010

Academic Editor: Norman Cameron

Copyright () 2010 Matthias Oelze et al. This is an open access article distributed under the Creative Commons Attribution License, which permits unrestricted use, distribution, and reproduction in any medium, provided the original work is properly cited.

Organic nitrates represent a class of drugs which are clinically used for treatment of ischemic symptoms of angina as well as for congestive heart failure based on the idea to overcome the impaired NO bioavailability by "NO" replacement therapy. The present paper is focused on parallels between diabetes mellitus and nitrate tolerance, and aims to discuss the mechanisms underlying nitrate resistance in the setting of diabetes. Since oxidative stress was identified as an important factor in the development of tolerance to organic nitrates, but also represents a hallmark of diabetic complications, this may represent a common principle for both disorders where therapeutic intervention should start. This paper examines the evidence supporting the hypothesis that pentaerithrityl tetranitrate may represent a nitrate for treatment of ischemia in diabetic patients. This evidence is based on the considerations of parallels between diabetes mellitus and nitrate tolerance as well as on preliminary data from experimental diabetes studies.

\section{Introduction}

1.1. Clinical and Economical Importance of Diabetes Mellitus. According to an estimation of the World Health Organization (WHO) in November 2009, more than 220 million people worldwide suffer from diabetes mellitus, a figure that will probably double by the year 2030 . The economic and human costs of this disease are devastating. WHO estimates that in the period 2006-2015, China will lose $\$ 558$ billion in foregone national income due to heart disease, stroke, and diabetes alone. The total cost of diabetes in the United States in 2002 was $\$ 132$ billion. According to the statistics of the NIH in 2007, 23 million Americans had diabetes, and the estimated lifetime risk for Americans born in 2000 to develop diabetes is 1 in 3 . In adults, diabetes is the most common cause of blindness, nontraumatic amputations, and end-stage renal disease as well as the sixth most common cause of death. In Germany, every 19 minutes a person with diabetes suffers a heart attack. With regard to these facts, it is of high clinical and economical importance, but also in the interest of the patients and their quality of life, to find new therapeutic options for the treatment of diabetes. Primarily, this research should be focused on the treatment of the metabolic disorder underlying diabetes to stop or slow down its progression. But also the treatment of diabetes symptoms and complications need to be addressed to improve the quality of life and prognosis of diabetic patients. Yet only limited knowledge exists about the pathogenesis, the cardiovascular consequences, and the prevention of this disease [1]. Recent data suggest that the cardiovascular complications in diabetes mellitus are associated with oxidative stress $[2,3]$, as previously shown for hypercholesterolemia and arteriosclerosis $[4,5]$. The sources of these reactive oxygen and nitrogen species (RONS) have been identified to be NADPH oxidases, mitochondria, xanthine oxidase, as well as an uncoupled endothelial nitric oxide synthase (eNOS) [6-8]. The present review will address the question whether organic nitrates may be used for treatment of diabetic patients, and if there are differences between the organic nitrates being in clinical use at present. 
1.2. Biochemical and Metabolic Consequences of Diabetes Mellitus. The relationship between diabetes and the resulting cardiovascular complications is complex, but damage to the vascular endothelium obviously plays a major role [9]. Chronic exposure of proteins from plasma and the cell membrane to hyperglycemia leads to the attachment of glucose molecules to proteins, a process known as nonenzymatic glycosylation. Subsequent slow reactions cause the formation of advanced glycation end products (AGEs) [10] known to inactivate nitric oxide (NO) and impair endothelium-dependent vasodilation [11]. However, shortterm hyperglycemia leads to similar negative effects on vascular responses, suggesting that this is not the only mechanism [12]. It was shown that hyperglycemia inhibits eNOS-dependent NO formation in favour of superoxide production, leading to an impaired endothelium-dependent vasodilation [13]. Besides the formation of advanced glycation end-products and diacylglycerol (DAG), the simultaneous increase in production of reactive oxygen species (especially superoxide, $\mathrm{O}_{2}{ }^{--}$) contributes to inhibition and uncoupling of eNOS via depletion of $\mathrm{BH}_{4}$ (summarized in Figure 1). Moreover, in diabetic patients, a higher production of vasoconstrictive compounds, such as endothelin-1 and angiotensin-II, has been observed. The increase in DAG and angiotensin-II is a direct consequence of the activation of the renin-angiotensin-aldosterone system (RAAS) in the setting of diabetes [14], which is also closely related to endothelial dysfunction $[15,16]$. Since DAG is a potent activator of the protein kinase $C[17,18]$ with subsequent activation of the NADPH oxidase [19], RAAS-induced activation of this superoxide source was demonstrated by clinical [20] as well as animal experimental studies [21]. There is even some evidence that suppression of the RAAS is able to prevent the development or progression of diabetes mellitus type II in hypertensive patients [22]. The events taking place during activation of the RAAS are summarized in Figure 2.

Leukocyte infiltration into the vascular wall was also dramatically increased. The increased concentrations of cytokines and matrix metalloproteinases lead to a decreased synthesis and increased degradation of collagen in atherosclerotic plaques reducing the stability of the fibrous cover plate, finally causing plaque rupture, thrombus formation, and myocardial infarction. In addition, the thrombocytes in diabetic individuals are larger in size, express more glycoprotein receptors on the surface, and show more pronounced aggregation in response to different stimuli (for review see [23]). Patients with diabetes mellitus have a 2- to 4-fold increased risk for infarction, and the mechanistic basis for macrovascular complications is progression of atherosclerosis. Endothelial dysfunction is a hallmark in the early stage of diabetes mellitus type 1 and 2 [24]. Oxidative protein modifications such as 3nitrotyrosine formation [25], oxidative disruption of the zinc-sulphur-cluster, and uncoupling of eNOS [26] as well as increased levels of toxic aldehydes [27] are common features of diabetes and may contribute to the observed disorders. A broad variety of different antioxidants have been demonstrated to beneficially influence diabetic complications [27-30].

\section{Organic Nitrates}

2.1. Clinical Use of Organic Nitrates. Nitroglycerin (glyceryl trinitrate) and the long-acting nitrates (isosorbide5-mononitrate [ISMN], isosorbide dinitrate [ISDN], and pentaerithrityl tetranitrate [PETN]) have been used in cardiovascular medicine for $>100$ years. Despite the fact that the potential mechanisms for relief of myocardial ischemia with nitrates are multiple and not yet fully understood [32], nitrates are widely utilized for the various anginal syndromes, and are also used in congestive heart failure and in patients with left ventricular dysfunction [33,34]. The nitrovasodilators are a group of drugs that result in the formation of $\mathrm{NO}$ or a related species within vascular smooth muscle cells [35]. Following the discovery of endotheliumderived NO [36], the idea of NO being the active principle of nitrates was very attractive to the scientific community, and it led to the speculation that they may replace a compromised endothelial NO production [37], such as in patients with coronary heart disease. Nitrates also have antiaggregatory effects, and recent evidence confirms that these drugs decrease platelet aggregation and thrombosis formation [38], although for nitroglycerin, an activation of thrombocytes was described $[39,40]$. This may play an important role in the therapy of acute unstable myocardial ischemia, including unstable angina and myocardial infarction. The hemodynamic effects of nitrates were known for a long time. They are primarily modulated by decreased myocardial work that results from smaller cardiac chambers that operate with lower systolic and diastolic pressures. These changes are secondary to a redistribution of the circulating blood volume from cardiac tissue to the venous capacitance system, with a decrease in venous return to the heart. The effects of nitrates on afterload as well as on arteries are also useful for the decrease in myocardial oxygen consumption. Considerable evidence supports a variety of mechanisms whereby nitrates lead to increased coronary blood flow, including stenosis enlargement, epicardial coronary artery dilation, improvement of endothelial dysfunction, enhanced collateral size and flow, and prevention or reversal of coronary artery vasoconstriction [33].

2.2. Bioactivation of Organic Nitrates. There is a consensus that the principle mechanism of organic nitrate-induced smooth muscle relaxation is achieved via NO signalling pathways, including activation of soluble guanylyl cyclase, increase in cyclic GMP levels and activation of cyclic GMPdependent protein kinases, and/or cyclic nucleotide-gated ion channels which was extensively reviewed [32]. Recently, the organic nitrate-derived NO hypothesis was challenged by two independent studies using state-of-the-art-methods to detect nitrate-derived NO formation which showed a huge discrepancy between nitroglycerin-derived $\mathrm{NO}$ and NO-induced vasodilation $[35,41]$. This, however, questions the relevance of nitroglycerin-derived $\mathrm{NO}$ formation in the clinically relevant concentration range whereas $\mathrm{NO}$ was detected for ISMN and ISDN during vasodilation of isolated aortic rings. For nitroglycerin, several bioactivating 


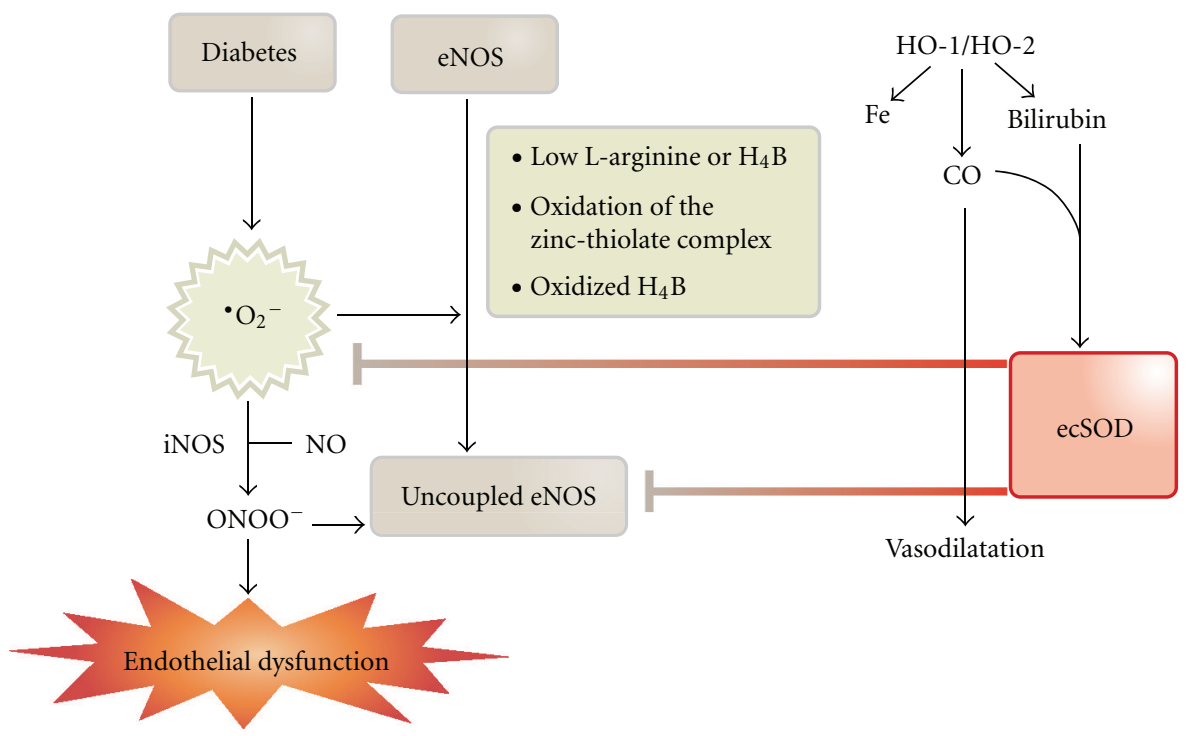

FIGURE 1: The scheme summarizes the simplified mechanisms underlying oxidative stress-induced endothelial dysfunction (and probably nitrate resistance) in diabetes mellitus. It should be noted that the oxidative stress concept provides an explanation for a part of diabetic complications and probably represents one important pathological pathway among several. Prevention of diabetic cardiovascular complications by induction of the heme oxygenase antioxidant system. Key mediators of these beneficial effects are carbon monoxide (CO) bilirubin, extracellular superoxide dismutase (ecSOD), coupling of endothelial NO synthase (eNOS) by normalization of tetrahydrobiopterin $\left(\mathrm{H}_{4} \mathrm{~B}\right)$ levels, and decrease in superoxide levels. Adopted from Abraham and Kappas, Pharmacol. Rev. 2008 [31].

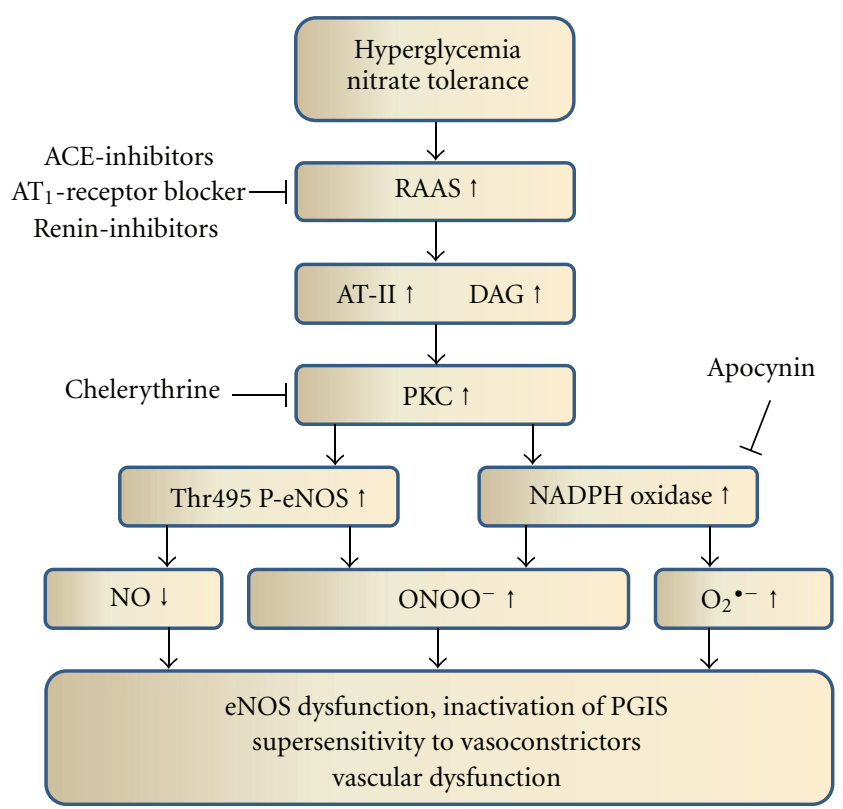

FIGURE 2: Sequence of events during activation of the renin-angiotensin-aldosterone system (RAAS) in the setting of hyperglycemia (diabetes mellitus type 1 and 2) or nitrate tolerance. Some therapeutic and experimental interventions are also shown. AT-II: angiotensin-II; DAG: diacylglycerol; PKC: protein kinase C; Thr495 P-eNOS: threonine495-phosphorylated endothelial NO synthase; $\mathrm{NO}$ nitric oxide; $\mathrm{O}_{2}{ }^{-{ }^{-}}$: superoxide; $\mathrm{ONOO}^{-}$: peroxynitrite; PGIS: prostacyclin.

systems have been proposed during the last decades including xanthine oxidoreductase, glutathione-S-transferases, and cytochrome P450 enzymes (for review see [32, 34]). It should be noted that these reports on nitroglycerin-derived NO formation were based on high suprapharmacological concentrations $(>10 \mu \mathrm{M})$ of the nitrate. Mononitrates and dinitrates have been reported to be mainly bioactivated by cytochrome P450 enzymes. In 2002, the mitochondrial aldehyde dehydrogenase (ALDH-2) was identified as an organic nitrate bioactivating enzyme [42]. This so-called nitrate reductase activity denitrates nitroglycerin to its 1,2 glycerol dinitrate metabolite and nitrite. This reaction relies 
on reduced thiols at the active site of the enzyme and on the presence of reduced dithiols as the electron source. During bioconversion of nitroglycerin, but also in the presence of reactive oxygen and nitrogen species, the active site thiols of ALDH-2 are oxidized, and the enzyme loses its activity [43]. Interestingly, ALDH-2 bioactivates nitroglycerin, PETN, and its trinitrate metabolite PETriN but not ISMN and ISDN [44], which could explain the different potency of these nitrates.

\subsection{Clinical Tolerance, Endothelial Dysfunction, and Dif-} ferences between Organic Nitrates. Tolerance and crosstolerance to endothelium-dependent vasodilators (endothelial dysfunction) are a major limitation for chronic nitrate treatment. Clinical tolerance and cross-tolerance may involve counterregulatory mechanisms (pseudotolerance) including release of catecholamines and activation of the reninangiotensin-aldosterone system (RAAS) making these phenomena even more complicated [32]. The first evidence for an involvement of the renin-angiotensin-aldosteronesystem (RAAS) in GTN-induced nitrate tolerance came from observations that long-term inhibition of angiotensinconverting enzyme improves nitrate tolerance in dogs [45, 46]. Additional studies showed that $\mathrm{AT}_{1}$-receptor blockade and ACE inhibition positively influence the development of tolerance, and it was hypothesized that this protective effect is mediated via inhibition of NADPH oxidase-dependent ROS formation [45, 47-53]. In contrast, there is a limited number of studies reporting on lack of effect of ACE inhibitors and $\mathrm{AT}_{1}$-receptor blockers on nitrate tolerance [54-56] and nitrate-induced oxidative stress [57]. Downstream to the RAAS system is the protein kinase C (PKC), which was also identified as an important constituent in the development and maintenance of GTN-induced nitrate tolerance [58-60]. Moreover, it was demonstrated that GTN-induced activation of PKC mediates late preconditioning, a protective effect which is probably based on initial ROS formation and mild oxidative damage [61]. The contribution of $\mathrm{NAD}(\mathrm{P}) \mathrm{H}$ oxidases to ROS production and oxidative damage in response to GTN therapy was established by a number of independent studies [62-64]. Nevertheless, NADPH oxidase, as a source of ROS formation in the setting of tolerance, was questioned since DPI, an unspecific inhibitor of flavindependent oxidoreductases, could not prevent the impaired response to GTN in tolerant vessels ex vivo [65]. In summary, the majority of previous work supports the contribution of the RAAS, PKC, and NADPH oxidase to the development of nitrate tolerance (the sequence of events is provided in Figure 2) although some studies neglect the importance of this pathway.

Tolerance and/or endothelial dysfunction have been observed in response to chronic treatment with nitroglycerin [66, 67], ISMN [68], and ISDN [69] (studies before 1990 reviewed in [70]) whereas no tolerance phenomena or markers such as oxidative stress were observed for long-term administration of PETN $[67,71]$. These reports indicate that tolerance development is uniform to all organic nitrates if applied in clinically effective dosage for longer periods of time. A remarkable exception seems to be PETN [72]. Some of these effects are related to special pharmacokinetics of PETN [73, 74], but, upon chronic administration, PETN also induces antioxidant pathways at the genomic level and cardioprotective genes (e.g., Apex1 and NFAT5) [75]. Among these induced antioxidant genes are heme oxygenase1 (HO-1) and ferritin [76], both possessing highly protective properties. There is good experimental evidence that at least part of the beneficial profile of long-term PETN treatment is based on activation of the heme oxygenase-1/ferritin system [77] and preliminary data in heme oxygenase-1 knockout mice support these previous findings. According to recent, unpublished data from our laboratory, PETN even acts differently at the purified ALDH-2, preventing inactivation of this nitrate reductase. Since ALDH-2, beyond bioactivating organic nitrates, was recently identified as an important protective enzyme, preventing ischemic damage in experimental myocardial infarction [78], the conservation of the enzymatic activity of ALDH-2 by an organic nitrate may be of great importance for long-term treatment of patients with ischemic heart disease. Nitroglycerin not only inactivates ALDH-2 but also downregulates the enzyme at the protein level [79]. More differences between organic nitrates in clinical use were recently discussed in detail [80]. The differences between nitroglycerin and PETN are summarized in Figure 3.

\subsection{Nitrate Tolerance and the "Oxidative Stress Concept".} The "oxidative stress concept" in the setting of nitrate tolerance was established by Munzel and colleagues [82] and refined during the last couple of years $[66,83]$. In essence, the concept consists of increased superoxide formation in response to nitrate treatment which decreases NO bioavailability, leads to peroxynitrite formation, NOS uncoupling, and impairs NO/cyclic GMP signalling [66]. Moreover, oxidative inhibition of prostacyclin synthase [84] as well as mitochondrial ALDH activity [85] may present other key events in the development of nitrate tolerance. Previously, the vascular NADH oxidase was considered as the most important source of reactive oxygen species (ROS) in the setting of nitrate tolerance [32]. Today this concept has been extended to induction of mitochondrial oxidative stress by nitroglycerin treatment $[83,86]$ and a crosstalk between mitochondrial ROS with NADPH oxidases in the cytoplasmic membrane [87]. Induction of oxidative stress was also described for ISMN in experimental hypertension [88], and indirect evidence was presented recently by demonstrating that the antioxidant vitamin $\mathrm{C}$ reverses ISMN-induced endothelial dysfunction in healthy volunteers [68]. However, until now, there is no direct proof for induction of oxidative stress by ISMN from clinical trials [89]. For ISDN, increased activation of NADPH oxidase was demonstrated in experimental MI as well as the adverse effects of the nitrate on the function of endothelial progenitor cells [90] although previous work by Keimer et al. revealed no induction of oxidative stress under ISDN or PETN therapy in healthy volunteers [91]. Indirect evidence for a role of oxidative stress in ISDN therapy comes from the highly beneficial effects of hydralazine combination therapy [92] since hydralazine is a powerful antioxidant [93] and has been 


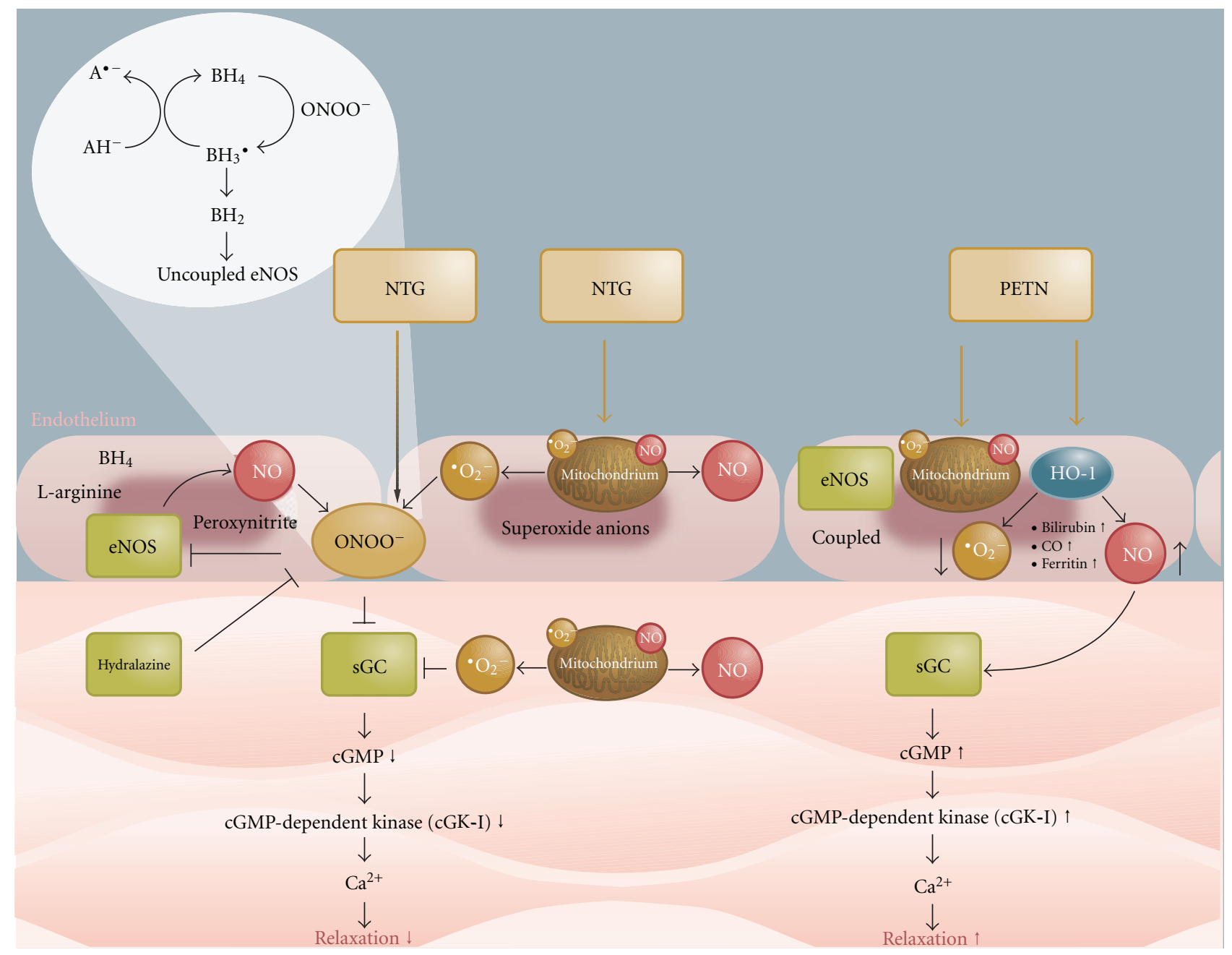

FIGURE 3: Vasodilation by nitroglycerin (NTG) and PETN: bioactivation to NO or a related species with subsequent activation of soluble guanylyl cyclase (sGC) and smooth muscle relaxation. Mechanisms underlying induction of vascular dysfunction by nitroglycerin and prevention of these adverse effects by activation of antioxidant, protective pathways by PETN: nitroglycerin induces mitochondrial and NADPH oxidase-dependent oxidative stress leading to uncoupling of eNOS and desensitization of sGC. PETN prevents these harmful events by induction of the antioxidant principle heme oxygenase and ferritin as well as others which are not shown here. Adopted from Gori et al., Arzneimitteltherapie 2008 [81].

demonstrated to prevent nitroglycerin-induced tolerance [62]. Related to these observations on adverse effects of nitrate therapy, Nakamura et al. presented evidence that long-term nitrate therapy increases cardiovascular mortality based on a retrospective analysis using databases from two large-scale postinfarction studies [94]. It should be noted that this analysis did not distinguish between different nitrates although there is increasing evidence that organic nitrates should not be treated as a homogenous class of compounds. Moreover, it is important to keep in mind that PETN did not share the adverse effects of the other nitrates since it was devoid of tolerance $[67,71,74]$, induction of oxidative stress $[71,90]$ and downregulation of protective genes $[75,77]$. Recent data has shown that nitroglycerin and PETN, although both considered as NO donors, exert completely opposite effects with respect to gene regulation:
PETN in vivo treatment induced cardioprotective genes (e.g., Apex1 and NFAT5) whereas nitroglycerin in vivo administration induced cardiotoxic genes (e.g., Egr1, fos, junD, and MITF) [75]. Another highly important property of PETN may be the induction of the extracellular superoxide dismutase (ecSOD) [95] and glutathione peroxidase (GPx) [96], two highly protective antioxidant proteins. These experimental and clinical data on the beneficial effects of PETN were recently supported by the double-blind, placebo-controlled PENTA study conducted by Warnholtz and colleagues with the main finding that chronic PETN treatment does not induce endothelial dysfunction or nitrate tolerance, but even improves GTN potency [97]. Relative changes in mean flow volume and mean flow velocity upon ischemia increased in the PETN group versus controls. 


\section{Use of Organic Nitrates for Therapy of Diabetic Patients}

3.1. Nitrate Resistance and Diabetes. The endothelial dysfunction present in hypercholesterolemic, type 2 diabetic, smoking, and ischemic heart disease patients reflects the reduced nitric oxide bioavailability, which can be assessed by different methods [98]. Patients with chronic heart failure did not show a significant effect in response to the NOS inhibitor $\mathrm{N}^{\mathrm{G}}$-methyl-L-arginine suggesting that $\mathrm{NO}$ does not contribute to basal vascular tone in these individuals. The responses to nitroglycerin and to serotonin were impaired, suggesting that there is smooth muscle dysfunction and endothelial dysfunction in patients with chronic heart failure [99]. Nitrate tolerance can be seen as an extreme example of nitrate resistance [100], and is thought, at least in part, to be secondary to the increased oxidative stress present in the aforementioned disease states. Thus, clinical nitrate tolerance and nitrate-induced activation of the renin-angiotensinaldosterone system (RAAS) as well as increased oxidant stress (see Section 2.3) may be regarded as an extension of the primary pathophysiological phenomenon of nitric oxide resistance (see Figure 2) [100]. Since diabetes is also associated with severe activation of the RAAS (see Section 1.2), the effects of diabetes and nitrate therapy could be additive and further impair endothelial function as well as nitrate potency. Hence, the potency of nitrates may be blunted by an underlying primary $\mathrm{NO}$ resistance to give a "primary" nitrate tolerance [101] whereas the mechanistically similar "secondary" nitrate tolerance (pseudotolerance) develops under chronic treatment [102]. These two nitrate tolerance states can even occur within the same patient. However, to date, it is not completely clarified whether pseudotolerance (secondary nitrate tolerance) contributes to endothelial dysfunction in response to an impaired NO responsiveness (NO resistance). However, evidence supporting this notion comes from a multivariate analysis of two observational coronary secondary prevention studies which showed increased mortality in chronically nitrate-treated ischemic heart disease patients following recovery from an acute cardiac event [94]. Also, a randomized controlled trial was performed and showed that continuous nitroglycerin treatment leads to endothelial dysfunction in both ischemic heart disease patients [103] and healthy volunteers [104]. In a series of experiments, impaired vasodilator responses to nitroglycerin were demonstrated in patients with diabetes mellitus when compared with age and sex matched controls $[105,106]$.

These impaired responses were somewhat surprising since nitrate-induced vasodilation has been shown to be increased when the endothelium is damaged and diabetes is associated with impaired endothelial function [9]. A possible explanation may be that the biotransformation of organic nitrates requires intracellular sulfhydryl groups in order to produce vasoactive intermediates [107]. Oxidative depletion of these sulfhydryl donors will cause impaired responsiveness to organic nitrates. In diabetes antioxidant activity is decreased [108]. The increase in oxidative stress and free radical activity that occurs in diabetes probably alters the redox equilibrium of intracellular thiols leading to primary oxidation or depletion of these essential sulfhydryl donors. But also succination of thiols may contribute to decreased sulfhydryl concentration [109]. Depletion of thiols is also envisaged in rats with streptozotocin-induced experimental diabetes that have significantly decreased serum antioxidant capacity (which largely depends on serum thiol groups) (unpublished observations, Oelze and Daiber). This is one possible explanation for an impaired nitrate response observed in diabetes [102, 105]. According to the recent development in the nitrate field, the mitochondrial nitrate reductase ALDH-2 could play a role as well. This enzyme requires dithiols (e.g., dihydrolipoic acid) in order to bioactivate nitroglycerin or PETN [43] and depletion of the pool of reduced thiols would probably lead to impairment of enzymatic activity. Although PETN also requires dithiols for bioactivation, this organic nitrate has slow pharmacokinetics preventing an overcharge of the bioactivating capacity of the organism $[74,110]$. This hypothesis is in accordance with the recent observation that $\mathrm{ALDH}-2$ activity is decreased in the testis of diabetic animals [111] although this observations needs further animal experimental or clinical verification in vascular tissue. Vice versa, inactivation of ALDH-2 by nitroglycerin was demonstrated to increase the infarct area in experimental MI [78] and ALDH-2 activation is related to $\mathrm{PKC} \varepsilon$ [112]. Recently, Ma et al. have demonstrated that ALDH-2 knockout aggravated, and ALDH-2 overexpression improved, ischemic damage in response to experimental MI [113]. Interestingly, these authors revealed a correlation between ALDH-2 and AMP-activated kinase (AMPK), which is an important metabolic enzyme involved in the management of disease states such as diabetes [114-116]. Besides the loss of AMPK activity by GTN-induced inactivation of ALDH-2, diabetic complications could be further aggravated by impaired breakdown of toxic aldehydes-it may be speculated that inhibition of ALDH-2 and AMPK may contribute to increased mortality of diabetic patients. In conclusion, for patients with congestive cardiac failure, type II diabetes and acute myocardial infarction resistance to the action of organic nitrates was demonstrated. In addition, there is good evidence that a significant percentage of normal subjects have impaired organic nitrate vasodilator potency [117].

3.2. Effectiveness of Antioxidants in Diabetes- and NitrateAssociated Vascular Complications. It was previously shown for the setting of nitrate tolerance and diabetes that there is increased formation of reactive oxygen species and/or decreased breakdown of those species leading to oxidative stress [2, 3, 66, 82]. Accordingly, there is a large number of studies demonstrating that cotreatment with antioxidants ameliorates nitrate- and diabetes-induced vascular oxidative stress and dysfunction. Examples include the use of direct antioxidants such as hydralazine [62, 93], vitamin C [40], superoxide dismutase [82], N-acetylcysteine [118], ebselen [84], and drugs with indirect antioxidant properties such as statins [119], $\mathrm{AT}_{1}$-receptor antagonists [59], ACE inhibitors [52], and the $\beta$-blocker carvedilol [120] (more compounds are reviewed in [32]). The antioxidant lipoic acid could 
improve nitrate tolerance which could be partially due to the fact that lipoic acid is the reducing cofactor of the nitrate bioactivating enzyme ALDH-2 $[43,74,121]$. It should be also noted that NO itself is a highly potent superoxide scavenger, although the resulting formation of peroxynitrite may limit the importance of this antioxidant property. Accordingly, organic nitrates with high turnover to NO may provide intrinsic antioxidant effects. The important role of oxidative stress for the development and progression of nitrate tolerance was further supported at a molecular level by the observation that vascular dysfunction in response to nitroglycerin was improved by genetic deletion of $\mathrm{p} 47^{\text {phox }}$, an essential subunit of the superoxide generating NADPH oxidase (Nox2) [87]. In contrast, genetic deletion of the important mitochondrial antioxidant protein manganese superoxide dismutase (MnSOD) caused an additional aggravation of nitrate-induced vascular dysfunction [83]. Interestingly, diabetes shows a very similar responsiveness to antioxidant treatment indicating that similar mechanisms as in nitrate tolerance account for vascular complications in diabetic patients and animals (see the aforementioned triggers for nitrate resistance and endothelial dysfunction). Improvement of vascular dysfunction and oxidative stress in diabetes was shown for direct antioxidants such as vitamin C [122, 123], lipoic acid [28, 124], ebselen [25], N-acetylcysteine [125], glutathione [126], and drugs with indirect antioxidant properties such as statins [127], $\mathrm{AT}_{1}$-receptor antagonists, or ACE inhibitors $[8,21,128]$. It should be noted that vitamin $\mathrm{C}$ was infused at high doses whereas oral administration did not improve endothelial dysfunction in diabetic patients [129] and even increased mortality in diabetic women [130]. Further evidence for an important role of oxidative stress for diabetic complications was provided at a molecular level by demonstrating that oxidative modifications contributing to diabetic retinopathy were prevented by overexpression of the MnSOD in a transgenic mouse model [131]. Likewise cardiomyocyte function and oxidative stress were beneficially influenced by overexpression of catalase in experimental models of type 1 and 2 diabetes [29]. Based on these data, there are striking parallels between nitrate tolerance and diabetes mellitus that converge at the level of oxidative stress as well as vascular dysfunction, which may explain nitrate resistance in the setting of diabetes. In accordance with these considerations, the clinical study of Picano and coworkers demonstrated that diabetes and nitrate therapy evoke synergistic oxidative DNA damage [132] suggesting that the pathophysiological mechanisms are similar in the setting of diabetes and nitrate tolerance. Comparable observations were made in atherosclerotic rabbits where nitroglycerin treatment synergistically increased the protein tyrosine nitration (a marker for peroxynitrite formation) in hyperlipidemic animals [133].

\subsection{Is Diabetes Mellitus Another Battlefield for Pentaerithrityl} Tetranitrate? As discussed above, the use of organic nitrates in diabetic patients is associated with certain risks: besides reduced efficacy of the drugs due to nitrate resistance in these individuals, there might be synergistic damage to the vascular system since nitrate treatment and diabetes both are associated with oxidative complications. Since PETN is devoid of tolerance [67], oxidative stress [71] and even normalized vascular function in experimental atherosclerosis [134], it might be expected that this nitrate demonstrates beneficial effects in the setting of diabetes. Considering the mechanisms underlying the protective effects of PETN, mainly based on induction of HO-1 [77], ferritin [135], ecSOD [95], and other protective genes/proteins [75] as discussed afore (summarized in Figure 1), PETN indeed could be a suitable nitrate for treatment of ischemia in diabetic patients. Heme oxygenase-1 induction by hemin was also able to suppress nitroglycerin-induced tolerance [77]. Of note are the observations that induction heme oxygenase lead to increased expression of ecSOD [31], and pharmacological as well as genetic overexpression of heme oxygenase protects from diabetic cardiovascular complications [31, 136] (summarized in Figure 1), whereas genetic deficiency in HO-1 aggravates myocardial ischemia/reperfusion injury in diabetic mice [137]. Therefore, it may be speculated that PETN-induced heme oxygenase- 1 and ecSOD induction are able to improve vascular function, redox state and even prognosis in diabetic patients. According to an ongoing study in our laboratory, PETN, in contrast to ISMN, is able to improve vascular complications in experimental diabetes. PETN corrected endothelial dysfunction by approximately $50 \%$ and improved nitrate resistance almost completely whereas ISMN had only minor effects on vascular dysfunction. Vascular and cardiac mitochondrial ROS formation as well as cardiac NADPH oxidase and serum xanthine oxidase activities were significantly improved by PETN whereas ISMN even increased NADPH oxidase activity. There is also evidence that PETN improves eNOS function and normalizes endothelial dysfunction in experimental diabetes via restoration of tetrahydrobiopterin levels, probably by preventing oxidative depletion of $\mathrm{BH}_{4}$ and upregulation of GTP-cyclohydrolase, the $\mathrm{BH}_{4}$ synthesizing enzyme. These beneficial effects of PETN on eNOS function, NADPH oxidase activity, and oxidative stress have recently been demonstrated for experimental hypertension in angiotensinII infused rats [138]. To our best knowledge, this was the first report on the improvement of angiotensin-II-induced hypertension by an organic nitrate.

\section{Conclusion and Clinical Implications}

The endothelium plays a pivotal role in modulating the reactivity of vascular smooth muscle through the formation of several vasoactive substances. There is good evidence for endothelial and smooth muscle dysfunction in diabetes which is shared by the pharmacologically-induced phenomenon of nitrate tolerance. Oxidative stress plays an important role in the setting of both vascular complications and may explain the presence of nitrate resistance in diabetic vessels, a major drawback for the use of nitrates in diabetic patients. Since nitrate tolerance as well as diabetes-associated vascular dysfunction nicely respond to antioxidant treatment, this may be the key to improve the safety and efficacy of a given organic nitrate in diabetic patients. One strategy could be a combination therapy of an antioxidant (e.g., 
hydralazine or lipoic acid) for which a relief of nitrate tolerance has been previously demonstrated. The combination of ISDN and hydralazine improved the efficacy of the nitrate dramatically in black patients with heart failure. Another promising attempt would be the use of pentaerithrityl tetranitrate which is devoid of nitrate tolerance and oxidative stress due to induction of antioxidant pathways (e.g., HO-1 and ecSOD). It remains to be established whether these highly promising observations, that are mainly based on animal experimental data, may be translated to the clinical situation. First evidence for beneficial effects of PETN treatment in diabetic patients comes from a cost comparison analysis contrasting PETN and ISDN prescribed to diabetic patients in primary care practices in Germany [139]. PETN therapy tended to produce a saving in costs compared to ISDN therapy in diabetic patients when costs for comedication were taken into account and after adjustment for age and comorbidity. Future effort may also be directed towards the development of new organic nitrates that are devoid of tolerance and oxidative stress. A promising strategy is the synthesis of hybrid molecules by introduction of a nitrate function into established cardiovascular drugs such as $\mathrm{AT}_{1}$-receptor blockers or glitazones (both drug classes have been demonstrated to prevent the development of nitrate tolerance). These compounds not only could possess intrinsic antioxidant effects, but also provide synergistic antihypertensive, antihyperglycemic, and antiatherosclerotic effects.

\section{Glossary}

Clinical nitrate tolerance: impaired vasodilatory potential of a given organic nitrate in response to chronic use of the drug (may comprise of "pseudotolerance," "NO resistance," "endothelial dysfunction" and impaired nitrate bioactivation).

Nitrate tachyphylaxis: fast onset of in vitro or in vivo tolerance due to high-dose acute treatment with an organic nitrate (most probably comprises of impaired nitrate bioactivation).

Primary tolerance: resistance of the vasculature to endogenous and/or exogenous vasodilators encountered in certain pathophysiological states such as diabetes or coronary artery disease. This primary tolerance may be directed to organic nitrates termed "nitrate resistance" or to other NO donors as well as endogenous NO formation termed "NO resistance."

Secondary tolerance: resistance of the vasculature to exogenous vasodilators encountered after prolonged (clinical tolerance) or high-dose (tachyphylaxis) use of these drugs. This secondary tolerance may be directed to organic nitrates termed "nitrate tolerance" or to other vasodilators generally termed "desensitization."

Pseudotolerance: loss of vasodilatory potential of a given drug due to humoral counterregulation (e.g., activation of the RAAS). Pseudotolerance is closely correlated with the "rebound phenomenon" upon withdrawal of the drug.

NO resistance: inadequate vasodilatory response of the vasculature to exogenous or endogenous nitric oxide encountered in certain pathophysiological states such as diabetes or coronary artery disease or upon development of "secondary tolerance."

Nitrate resistance: special form of "primary tolerance." Inadequate vasodilatory response of the vasculature to exogenous organic nitrate therapy encountered in certain pathophysiological states such as diabetes or coronary artery disease or upon development of "secondary tolerance."

Endothelial dysunction: inadequate vasodilatory response of the vasculature to exogenous or endogenous endothelium-dependent vasodilators encountered in certain pathophysiological states such as diabetes or coronary artery disease or upon chronic use of organic nitrates (e.g., "cross-tolerance" to acetylcholine).

\section{Conflict of Interests}

A. Daiber received vascular research grants and lecture fees from Actavis Deutschland GmbH.

\section{Abbreviations}

ACE: Angiotensin-converting enzyme

ALDH-2: Mitochondrial aldehyde dehydrogenase

ecSOD: Extracellular superoxide dismutase (copper, zinc-containing)

eNOS: Endothelial nitric oxide synthase

HO-1: Heme oxygenase-1

ISMN: Isosorbide-5-mononitrate

ISDN: Isosorbide dinitrate

MnSOD: Manganese superoxide dismutase (mitochondrial isoform)

NO: $\quad$ Nitric oxide (nitrogen monoxide)

PETN: Pentaerithrityl tetranitrate

RAAS: Renin-angiotensin-aldosterone system

ROS: $\quad$ Reactive oxygen species.

\section{Acknowledgments}

The support by research grants from the Medical Center of the Johannes Gutenberg University (MAIFOR and Forschungsfonds) is gratefully acknowledged. Moreover, the authors would like to thank Actavis Deutschland $\mathrm{GmbH}$ for continuous financial support of their organic nitrate research. The authors are also indebted to Thilo Weckmüller and Margot Neuser, their graphic artists, for preparing the schemes.

\section{References}

[1] A. S. de Vriese, T. J. Verbeuren, J. van de Voorde, N. H. Lameire, and P. M. Vanhoutte, "Endothelial dysfunction in diabetes," British Journal of Pharmacology, vol. 130, no. 5, pp. 963-974, 2000.

[2] J. F. Keaney Jr. and J. Loscalzo, "Diabetes, oxidative stress, and platelet activation," Circulation, vol. 99, no. 2, pp. 189-191, 1999.

[3] B. Lipinski, "Pathophysiology of oxidative stress in diabetes mellitus," Journal of Diabetes and Its Complications, vol. 15, no. 4, pp. 203-210, 2001. 
[4] K. K. Griendling and G. A. FitzGerald, "Oxidative stress and cardiovascular injury-part II: animal and human studies," Circulation, vol. 108, no. 17, pp. 2034-2040, 2003.

[5] T. Heitzer, T. Schlinzig, K. Krohn, T. Meinertz, and T. Münzel, "Endothelial dysfunction, oxidative stress, and risk of cardiovascular events in patients with coronary artery disease," Circulation, vol. 104, no. 22, pp. 2673-2678, 2001.

[6] F. Pricci, G. Leto, L. Amadio et al., "Oxidative stress in diabetes-induced endothelial dysfunction involvement of nitric oxide and protein kinase C," Free Radical Biology and Medicine, vol. 35, no. 6, pp. 683-694, 2003.

[7] Y. Yu and T. J. Lyons, "A lethal tetrad in diabetes: hyperglycemia, dyslipidemia, oxidative stress, and endothelial dysfunction," American Journal of the Medical Sciences, vol. 330, no. 5, pp. 227-232, 2005.

[8] P. Wenzel, E. Schulz, M. Oelze et al., "AT1-receptor blockade by telmisartan upregulates GTP-cyclohydrolase I and protects eNOS in diabetic rats," Free Radical Biology and Medicine, vol. 45, no. 5, pp. 619-626, 2008.

[9] G. D. Johnston, "Ulster says 'NO'; explosion, resistance and tolerance: nitric oxide and the actions of organic nitrates," Ulster Medical Journal, vol. 67, no. 2, pp. 79-90, 1998.

[10] J. Uitto, A. J. Perejda, G. A. Grant, E. A. Rowold, C. Kilo, and J. R. Williamson, "Glycosylation of human glomerular basement membrane collagen: increased content of hexose in ketoamine linkage and unaltered hydroxylysine-O-glycosides in patients with diabetes," Connective Tissue Research, vol. 10, no. 3-4, pp. 287-296, 1982.

[11] R. Bucala, K. J. Tracey, and A. Cerami, "Advanced glycosylation products quench nitric oxide and mediate defective endothelium-dependent vasodilatation in experimental diabetes," Journal of Clinical Investigation, vol. 87, no. 2, pp. 432 438, 1991.

[12] P. D. Taylor and L. Poston, "The effect of hyperglycaemia on function of rat isolated mesenteric resistance artery," British Journal of Pharmacology, vol. 113, no. 3, pp. 801-808, 1994.

[13] U. Hink, H. Li, H. Mollnau et al., "Mechanisms underlying endothelial dysfunction in diabetes mellitus," Circulation Research, vol. 88, no. 2, pp. E14-E22, 2001.

[14] A. H. Barnett, S. C. Bain, P. Bouter et al., "Angiotensinreceptor blockade versus converting-enzyme inhibition in type 2 diabetes and nephropathy," New England Journal of Medicine, vol. 351, no. 19, pp. 1952-1961, 2004.

[15] M. J. Crespo and D. C. Dunbar, "Enalapril improves vascular and cardiac function in streptozotocin-diabetic rats," Cellular and Molecular Biology, vol. 49, no. 8, pp. 1311-1318, 2003.

[16] A. Ceriello, R. Assaloni, R. da Ros et al., "Effect of atorvastatin and irbesartan, alone and in combination, on postprandial endothelial dysfunction, oxidative stress, and inflammation in type 2 diabetic patients," Circulation, vol. 111, no. 19, pp. 2518-2524, 2005.

[17] H. Ishii, D. Koya, and G. L. King, "Protein kinase C activation and its role in the development of vascular complications in diabetes mellitus," Journal of Molecular Medicine, vol. 76, no. 1, pp. 21-31, 1998.

[18] D. Koya and G. L. King, "Protein kinase C activation and the development of diabetic complications," Diabetes, vol. 47, no. 6, pp. 859-866, 1998.

[19] T. Inoguchi, P. Li, F. Umeda et al., "High glucose level and free fatty acid stimulate reactive oxygen species production through protein kinase C-dependent activation of $\mathrm{NAD}(\mathrm{P}) \mathrm{H}$ oxidase in cultured vascular cells," Diabetes, vol. 49, no. 11, pp. 1939-1945, 2000.
[20] D. G. Harrison, H. Cai, U. Landmesser, and K. K. Griendling, "Interactions of angiotensin II with $\mathrm{NAD}(\mathrm{P}) \mathrm{H}$ oxidase, oxidant stress and cardiovascular disease," Journal of the Renin-Angiotensin-Aldosterone System, vol. 4, no. 2, pp. 5161, 2003.

[21] J. H. Oak and H. Cai, "Attenuation of angiotensin II signaling recouples eNOS and inhibits nonendothelial NOX activity in diabetic mice," Diabetes, vol. 56, no. 1, pp. 118-126, 2007.

[22] R. Nosadini and G. Tonolo, "The role of the renin angiotensin hormonal system in the metabolic syndrome and type 2 diabetes," Nutrition, Metabolism and Cardiovascular Diseases, vol. 14, no. 2, pp. 88-93, 2004.

[23] G. C. Fonarow, "An approach to heart failure and diabetes mellitus," American Journal of Cardiology, vol. 96, no. 4A, pp. 47E-52E, 2005.

[24] T. Heitzer, K. Krohn, S. Albers, and T. Meinertz, "Tetrahydrobiopterin improves endothelium-dependent vasodilation by increasing nitric oxide activity in patients with Type II diabetes mellitus," Diabetologia, vol. 43, no. 11, pp. 1435$1438,2000$.

[25] S. V. Brodsky, O. Gealekman, J. Chen et al., "Prevention and reversal of premature endothelial cell senescence and vasculopathy in obesity-induced diabetes by ebselen," Circulation Research, vol. 94, no. 3, pp. 377-384, 2004.

[26] J. Xu, Z. Xie, R. Reece, D. Pimental, and M. H. Zou, "Uncoupling of endothelial nitric oxidase synthase by hypochlorous acid: role of $\mathrm{NAD}(\mathrm{P}) \mathrm{H}$ oxidase-derived superoxide and peroxynitrite," Arteriosclerosis, Thrombosis, and Vascular Biology, vol. 26, no. 12, pp. 2688-2695, 2006.

[27] M. C. Desco, M. Asensi, R. Márquez et al., "Xanthine oxidase is involved in free radical production in type 1 diabetes: protection by allopurinol," Diabetes, vol. 51, no. 4, pp. 1118$1124,2002$.

[28] T. Heitzer, B. Finckh, S. Albers, K. Krohn, A. Kohlschütter, and T. Meinertz, "Beneficial effects of $\alpha$-lipoic acid and ascorbic acid on endothelium-dependent, nitric oxide-mediated vasodilation in diabetic patients: relation to parameters of oxidative stress," Free Radical Biology and Medicine, vol. 31, no. 1, pp. 53-61, 2001.

[29] G. Ye, N. S. Metreveli, R. V. Donthi et al., "Catalase protects cardiomyocyte function in models of Type 1 and Type 2 diabetes," Diabetes, vol. 53, no. 5, pp. 1336-1343, 2004.

[30] T. Nassar, B. Kadery, C. Lotan, N. Da'as, Y. Kleinman, and A. Haj-Yehia, "Effects of the superoxide dismutasemimetic compound tempol on endothelial dysfunction in streptozotocin-induced diabetic rats," European Journal of Pharmacology, vol. 436, no. 1-2, pp. 111-118, 2002.

[31] N. G. Abraham and A. Kappas, "Pharmacological and clinical aspects of heme oxygenase," Pharmacological Reviews, vol. 60, no. 1, pp. 79-127, 2008.

[32] T. Münzel, A. Daiber, and A. Mülsch, "Explaining the phenomenon of nitrate tolerance," Circulation Research, vol. 97, no. 7, pp. 618-628, 2005.

[33] J. Abrams, "Beneficial actions of nitrates in cardiovascular disease," American Journal of Cardiology, vol. 77, no. 13, pp. 31C-37C, 1996.

[34] A. Daiber, P. Wenzel, M. Oelze, and T. Münzel, "New insights into bioactivation of organic nitrates, nitrate tolerance and cross-tolerance," Clinical Research in Cardiology, vol. 97, no. 1, pp. 12-20, 2008.

[35] A. L. Kleschyov, M. Oelze, A. Daiber et al., "Does nitric oxide mediate the vasodilator activity of nitroglycerin?" Circulation Research, vol. 93, no. 9, pp. e104-e112, 2003. 
[36] R. M. J. Palmer, A. G. Ferrige, and S. Moncada, "Nitric oxide release accounts for the biological activity of endotheliumderived relaxing factor," Nature, vol. 327, no. 6122, pp. 524526, 1987.

[37] J. L. Mehta, "Endothelium, coronary vasodilation, and organic nitrates," American Heart Journal, vol. 129, no. 2, pp. 382-391, 1995.

[38] R. Gerzer, B. Karrenbrock, W. Siess, and J. M. Heim, "Direct comparison of the effects of nitroprusside, SIN 1, and various nitrates on platelet aggregation and soluble guanylate cyclase activity," Thrombosis Research, vol. 52, no. 1, pp. 11-21, 1988.

[39] E. Bassenge and B. Fink, "Tolerance to nitrates and simultaneous upregulation of platelet activity prevented by enhancing antioxidant state," Naunyn-Schmiedeberg's Archives of Pharmacology, vol. 353, no. 3, pp. 363-367, 1996.

[40] E. Bassenge, N. Fink, M. Skatchkov, and B. Fink, "Dietary supplement with vitamin C prevents nitrate tolerance," Journal of Clinical Investigation, vol. 102, no. 1, pp. 67-71, 1998.

[41] C. Núñez, V. M. Víctor, R. Tur et al., "Discrepancies between nitroglycerin and NO-releasing drugs on mitochondrial oxygen consumption, vasoactivity, and the release of NO," Circulation Research, vol. 97, no. 10, pp. 1063-1069, 2005.

[42] Z. Chen, J. Zhang, and J. S. Stamler, "Identification of the enzymatic mechanism of nitroglycerin bioactivation," Proceedings of the National Academy of Sciences of the United States of America, vol. 99, no. 12, pp. 8306-8311, 2002.

[43] P. Wenzel, U. Hink, M. Oelze et al., "Role of reduced lipoic acid in the redox regulation of mitochondrial aldehyde dehydrogenase (ALDH-2) activity: implications for mitochondrial oxidative stress and nitrate tolerance," Journal of Biological Chemistry, vol. 282, no. 1, pp. 792-799, 2007.

[44] P. Wenzel, U. Hink, M. Oelze et al., "Number of nitrate groups determines reactivity and potency of organic nitrates: a proof of concept study in ALDH-2 mice," British Journal of Pharmacology, vol. 150, no. 4, pp. 526-533, 2007.

[45] T. Münzel and E. Bassenge, "Long-term angiotensinconverting enzyme inhibition with high-dose enalapril retards nitrate tolerance in large epicardial arteries and prevents rebound coronary vasoconstriction in vivo," Circulation, vol. 93, no. 11, pp. 2052-2058, 1996.

[46] T. Münzel, H. Mollnau, M. Hartmann et al., "Effects of a nitrate-free interval on tolerance, vasoconstrictor sensitivity and vascular superoxide production," Journal of the American College of Cardiology, vol. 36, no. 2, pp. 628-634, 2000.

[47] G. Berkenboom, D. Fontaine, P. Unger, S. Baldassarre, N. Preumont, and J. Fontaine, "Absence of nitrate tolerance after long-term treatment with ramipril: an endotheliumdependent mechanism," Journal of Cardiovascular Pharmacology, vol. 34, no. 4, pp. 547-553, 1999.

[48] H. Watanabe, M. Kakihana, S. Ohtsuka, and Y. Sugishita, "Preventive effects of angiotensin-converting enzyme inhibitors on nitrate tolerance during continuous transdermal application of nitroglycerin in patients with chronic heart failure," Japanese Circulation Journal, vol. 62, no. 5, pp. 353-358, 1998.

[49] G. Cotter, E. Metzkor-Cotter, E. Kaluski et al., "Usefulness of losartan, captopril, and furosemide in preventing nitrate tolerance and improving control of unstable angina pectoris," American Journal of Cardiology, vol. 82, no. 9, pp. 1024-1029, 1998.

[50] L. Pizzulli, A. Hagendorff, M. Zirbes et al., "Influence of captopril on nitroglycerin-mediated vasodilation and development of nitrate tolerance in arterial and venous circulation," American Heart Journal, vol. 131, no. 2, pp. 342349, 1996.

[51] R. J. Katz, W. S. Levy, L. Buff, and A. G. Wasserman, "Prevention of nitrate tolerance with angiotensin converting enzyme inhibitors," Circulation, vol. 83, no. 4, pp. 1271-1277, 1991.

[52] A. Otto, J. Fontaine, and G. Berkenboom, "Ramipril treatment protects against nitrate-induced oxidative stress in eNOS mice: an implication of the NADPH oxidase pathway," Journal of Cardiovascular Pharmacology, vol. 48, no. 1, pp. 842-849, 2006.

[53] N. Hirai, H. Kawano, H. Yasue et al., "Attenuation of nitrate tolerance and oxidative stress by an angiotensin II receptor blocker in patients with coronary spastic angina," Circulation, vol. 108, no. 12, pp. 1446-1450, 2003.

[54] N. Dakak, N. Makhoul, M. Y. Flugelman et al., "Failure of captopril to prevent nitrate tolerance in congestive heart failure secondary to coronary artery disease," American Journal of Cardiology, vol. 66, no. 5, pp. 608-613, 1990.

[55] G. Longobardi, N. Ferrara, D. Leosco et al., "Angiotensin IIreceptor antagonist Losartan does not prevent nitroglycerin tolerance in patients with coronary artery disease," Cardiovascular Drugs and Therapy, vol. 18, no. 5, pp. 363-370, 2004.

[56] S. D. Milone, E. R. Azevedo, C. Forster, and J. D. Parker, "The angiotensin II-receptor antagonist losartan does not prevent hemodynamic or vascular tolerance to nitroglycerin," Journal of Cardiovascular Pharmacology, vol. 34, no. 5, pp. 645-650, 1999.

[57] S. D. Milone, C. R. Pace-Asciak, D. Reynaud, E. R. Azevedo, G. E. Newton, and J. D. Parker, "Biochemical, hemodynamic, and vascular evidence concerning the free radical hypothesis of nitrate tolerance," Journal of Cardiovascular Pharmacology, vol. 33, no. 5, pp. 685-690, 1999.

[58] T. Münzel and D. G. Harrison, "Evidence for a role of oxygen derived free radicals and protein kinase $\mathrm{C}$ in nitrate tolerance," Journal of Molecular Medicine, vol. 75, no. 11-12, pp. 891-900, 1997.

[59] S. Kurz, U. Hink, G. Nickenig, A. B. Borthayre, D. G. Harrison, and T. Münzel, "Evidence for a causal role of the renin-angiotensin system in nitrate tolerance," Circulation, vol. 99, no. 24, pp. 3181-3187, 1999.

[60] G. Abou-Mohamed, J. A. Johnson, L. Jin et al., "Roles of superoxide, peroxynitrite, and protein kinase $\mathrm{C}$ in the development of tolerance to nitroglycerin," Journal of Pharmacology and Experimental Therapeutics, vol. 308, no. 1, pp. 289-299, 2004.

[61] S. Banerjee, X. L. Tang, Y. Qiu et al., "Nitroglycerin induces late preconditioning against myocardial stunning via a PKCdependent pathway," American Journal of Physiology-Heart and Circulatory Physiology, vol. 277, no. 6, pp. H2488-H2494, 1999.

[62] T. Münzel, S. Kurz, S. Rajagopalan et al., "Hydralazine prevents nitroglycerin tolerance by inhibiting activation of a membrane-bound NADH oxidase: a new action for an old drug," Journal of Clinical Investigation, vol. 98, no. 6, pp. 1465-1470, 1996.

[63] M. Schwemmer and E. Bassenge, "New approaches to overcome tolerance to nitrates," Cardiovascular Drugs and Therapy, vol. 17, no. 2, pp. 159-173, 2003.

[64] A. Fukatsu, T. Hayashi, A. Miyazaki-Akita et al., "Possible usefulness of apocynin, an NADPH oxidase inhibitor, for 
nitrate tolerance: prevention of NO donor-induced endothelial cell abnormalities," American Journal of PhysiologyHeart and Circulatory Physiology, vol. 293, no. 1, pp. H790H797, 2007.

[65] J. D. Ratz, J. J. McGuire, D. J. Anderson, and B. M. Bennett, "Effects of the flavoprotein inhibitor, diphenyleneiodonium sulfate, on ex vivo organic nitrate tolerance in the rat," Journal of Pharmacology and Experimental Therapeutics, vol. 293, no. 2, pp. 569-577, 2000.

[66] E. Schulz, N. Tsilimingas, R. Rinze et al., "Functional and biochemical analysis of endothelial (Dys)function and NO/cGMP signaling in human blood vessels with and without nitroglycerin pretreatment," Circulation, vol. 105, no. 10, pp. 1170-1175, 2002.

[67] T. Gori, A. Al-Hesayen, C. Jolliffe, and J. D. Parker, "Comparison of the effects of pentaerythritol tetranitrate and nitroglycerin on endothelium-dependent vasorelaxation in male volunteers," American Journal of Cardiology, vol. 91, no. 11, pp. 1392-1394, 2003.

[68] G. R. Thomas, J. M. DiFabio, T. Gori, and J. D. Parker, "Once daily therapy with isosorbide-5-mononitrate causes endothelial dysfunction in humans. Evidence of a freeradical-mediated mechanism," Journal of the American College of Cardiology, vol. 49, no. 12, pp. 1289-1295, 2007.

[69] M. Sekiya, M. Sato, J. Funada, T. Ohtani, H. Akutsu, and K. Watanabe, "Effects of the long-term administration of nicorandil on vascular endothelial function and the progression of arteriosclerosis," Journal of Cardiovascular Pharmacology, vol. 46, no. 1, pp. 63-67, 2005.

[70] J. Ahlner, R. G. G. Andersson, K. Torfgard, and K. L. Axelsson, "Organic nitrate esters: clinical use and mechanisms of actions," Pharmacological Reviews, vol. 43, no. 3, pp. 351-423, 1991.

[71] U. Jurt, T. Gori, A. Ravandi, S. Babaei, P. Zeman, and J. D. Parker, "Differential effects of pentaerythritol tetranitrate and nitroglycerin on the development of tolerance and evidence of lipid peroxidation: a human in vivo study," Journal of the American College of Cardiology, vol. 38, no. 3, pp. 854-859, 2001.

[72] J. Müllenheim, S. Müller, U. Laber et al., "The effect of high-dose pentaerythritol tetranitrate on the development of nitrate tolerance in rabbits," Naunyn-Schmiedeberg's Archives of Pharmacology, vol. 364, no. 3, pp. 269-275, 2001.

[73] A. Koenig, K. Lange, J. Konter et al., "Potency and in vitro tolerance of organic nitrates: partially denitrated metabolites contribute to the tolerance-devoid activity of pentaerythrityl tetranitrate," Journal of Cardiovascular Pharmacology, vol. 50, no. 1, pp. 68-74, 2007.

[74] P. Wenzel, E. Schulz, T. Gori et al., "Monitoring white blood cell mitochondrial aldehyde dehydrogenase activity: implications for nitrate therapy in humans," Journal of Pharmacology and Experimental Therapeutics, vol. 330, no. 1, pp. 63-71, 2009.

[75] A. Pautz, P. Rauschkolb, N. Schmidt et al., "Effects of nitroglycerin or pentaerithrityl tetranitrate treatment on the gene expression in rat hearts: evidence for cardiotoxic and cardioprotective effects," Physiological Genomics, vol. 38, no. 2, pp. 176-185, 2009.

[76] S. Oberle, A. Abate, N. Grosser et al., "Endothelial protection by pentaerithrityl trinitrate: Bilirubin and carbon monoxide as possible mediators," Experimental Biology and Medicine, vol. 228, no. 5, pp. 529-534, 2003.
[77] P. Wenzel, M. Oelze, M. Coldewey et al., "Heme oxygenase1: a novel key player in the development of tolerance in response to organic nitrates," Arteriosclerosis, Thrombosis, and Vascular Biology, vol. 27, no. 8, pp. 1729-1735, 2007.

[78] C. H. Chen, G. R. Budas, E. N. Churchill, M. H. Disatnik, T. D. Hurley, and D. Mochly-Rosen, "Activation of aldehyde dehydrogenase-2 reduces ischemic damage to the heart," Science, vol. 321, no. 5895, pp. 1493-1495, 2008.

[79] U. Hink, A. Daiber, N. Kayhan et al., "Oxidative inhibition of the mitochondrial aldehyde dehydrogenase promotes nitroglycerin tolerance in human blood vessels," Journal of the American College of Cardiology, vol. 50, no. 23, pp. 22262232, 2007.

[80] T. Gori and A. Daiber, "Non-hemodynamic effects of organic nitrates and the distinctive characteristics of pentaerithrityl tetranitrate," American Journal of Cardiovascular Drugs, vol. 9, no. 1, pp. 7-15, 2009.

[81] T. Gori, T. Munzel, and A. Daiber, "Nicht-hämodynamische Wirkungen organischer Nitrate und unterschiedliche Charakteristika von Pentaerithrityltetranitrat," Arzneimitteltherapie, vol. 26, pp. 290-298, 2008.

[82] T. Munzel, H. Sayegh, B. A. Freeman, M. M. Tarpey, and D. G. Harrison, "Evidence for enhanced vascular superoxide anion production in nitrate tolerance. A novel mechanism underlying tolerance and cross-tolerance," Journal of Clinical Investigation, vol. 95, no. 1, pp. 187-194, 1995.

[83] A. Daiber, M. Oelze, S. Sulyok et al., "Heterozygous deficiency of manganese superoxide dismutase in mice (MnSOD+/-): a novel approach to assess the role of oxidative stress for the development of nitrate tolerance," Molecular Pharmacology, vol. 68, no. 3, pp. 579-588, 2005.

[84] U. Hink, M. Oelze, P. Kolb et al., "Role for peroxynitrite in the inhibition of prostacyclin synthase in nitrate tolerance," Journal of the American College of Cardiology, vol. 42, no. 10, pp. 1826-1834, 2003.

[85] A. Daiber, M. Oelze, M. Coldewey et al., "Oxidative stress and mitochondrial aldehyde dehydrogenase activity: a comparison of pentaerythritol tetranitrate with other organic nitrates," Molecular Pharmacology, vol. 66, no. 6, pp. 13721382, 2004.

[86] K. Sydow, A. Daiber, M. Oelze et al., "Central role of mitochondrial aldehyde dehydrogenase and reactive oxygen species in nitroglycerin tolerance and cross-tolerance," Journal of Clinical Investigation, vol. 113, no. 3, pp. 482-489, 2004.

[87] P. Wenzel, H. Mollnau, M. Oelze et al., "First evidence for a crosstalk between mitochondrial and NADPH oxidasederived reactive oxygen species in nitroglycerin-triggered vascular dysfunction," Antioxidants and Redox Signaling, vol. 10, no. 8, pp. 1435-1447, 2008.

[88] F. Reis, P. Rocha-Pereira, E. Teixeira de Lemos et al., "Oxidative stress in cyclosporine-induced hypertension: evidence of beneficial effects or tolerance development with nitrate therapy," Transplantation Proceedings, vol. 39, no. 8, pp. 2494-2500, 2007.

[89] E. Tingberg, A. K. Öhlin, A. Gottsäter, and H. Öhlin, "Lipid peroxidation is not increased in heart failure patients on modern pharmacological therapy," International Journal of Cardiology, vol. 112, no. 3, pp. 275-281, 2006.

[90] T. Thum, D. Fraccarollo, S. Thum et al., "Differential effects of organic nitrates on endothelial progenitor cells are determined by oxidative stress," Arteriosclerosis, Thrombosis, and Vascular Biology, vol. 27, no. 4, pp. 748-754, 2007. 
[91] R. Keimer, F. K. Stutzer, D. Tsikas, R. Troost, F. M. Gutzki, and J. C. Frölich, "Lack of oxidative stress during sustained therapy with isosorbide dinitrate and pentaerythrityl tetranitrate in healthy humans: a randomized, double-blind crossover study," Journal of Cardiovascular Pharmacology, vol. 41, no. 2, pp. 284-292, 2003.

[92] A. L. Taylor, S. Ziesche, C. Yancy et al., "Combination of isosorbide dinitrate and hydralazine in blacks with heart failure," New England Journal of Medicine, vol. 351, no. 20, pp. 2049-2141, 2004.

[93] A. Daiber, M. Oelze, M. Coldewey et al., "Hydralazine is a powerful inhibitor of peroxynitrite formation as a possible explanation for its beneficial effects on prognosis in patients with congestive heart failure," Biochemical and Biophysical Research Communications, vol. 338, no. 4, pp. 1865-1874, 2005.

[94] Y. Nakamura, A. J. Moss, M. W. Brown, M. Kinoshita, and C. Kawai, "Long-term nitrate use may be deleterious in ischemic heart disease: a study using the databases from two large-scale postinfarction studies," American Heart Journal, vol. 138, no. 3 , part 1, pp. 577-585, 1999.

[95] M. Oppermann, V. Balz, V. Adams et al., "Pharmacological induction of vascular extracellular superoxide dismutase expression in vivo," Journal of Cellular and Molecular Medicine, vol. 13, no. 7, pp. 1271-1278, 2009.

[96] I. Dovinová, S. Cačáanyiová, V. Fáberová, and F. Kristek, "The effect of an NO donor, pentaerythrityl tetranitrate, on biochemical, functional, and morphological attributes of cardiovascular system of spontaneously hypertensive rats," General Physiology and Biophysics, vol. 28, no. 1, pp. 86-93, 2009.

[97] B. Schnorbus, R. Schiewe, M. A. Ostad et al., "Effects of pentaerythritol tetranitrate on endothelial function in coronary artery disease: results of the PENTA study," Clinical Research in Cardiology, vol. 99, no. 2, pp. 115-124, 2010.

[98] H. Drexler and B. Hornig, "Endothelial dysfunction in human disease," Journal of Molecular and Cellular Cardiology, vol. 31, no. 1, pp. 51-60, 1999.

[99] S. M. Maguire, A. G. Nugent, C. McGurk, G. D. Johnston, and D. P. Nicholls, "Abnormal vascular responses in human chronic cardiac failure are both endothelium dependent and endothelium independent," Heart, vol. 80, no. 2, pp. 141145, 1998.

[100] K. E. Fayers, M. H. Cummings, K. M. Shaw, and D. W. Laight, "Nitrate tolerance and the links with endothelial dysfunction and oxidative stress," British Journal of Clinical Pharmacology, vol. 56, no. 6, pp. 620-628, 2003.

[101] J. B. Laursen, S. Boesgaard, H. E. Poulsen, and J. Aldershvile, "Nitrate tolerance impairs nitric oxide-mediated vasodilation in vivo," Cardiovascular Research, vol. 31, no. 5, pp. 814819, 1996.

[102] G. McVeigh, G. Brennan, R. Hayes, and D. Johnston, "Primary nitrate tolerance in diabetes mellitus," Diabetologia, vol. 37, no. 1, pp. 115-117, 1994.

[103] P. R. A. Caramori, A. G. Adelman, E. R. Azevedo, G. E. Newton, A. B. Parker, and J. D. Parker, "Therapy with nitroglycerin increases coronary vasoconstriction in response to acetylcholine," Journal of the American College of Cardiology, vol. 32, no. 7, pp. 1969-1974, 1998.

[104] T. Gori, S. S. Mak, S. Kelly, and J. D. Parker, "Evidence supporting abnormalities in nitric oxide synthase function induced by nitroglycerin in humans," Journal of the American College of Cardiology, vol. 38, no. 4, pp. 1096-1101, 2001.
[105] G. E. McVeigh, G. M. Brennan, G. D. Johnston et al., "Impaired endothelium-dependent and independent vasodilation in patients with Type 2 (non-insulin-dependent) diabetes mellitus," Diabetologia, vol. 35, no. 8, pp. 771-776, 1992.

[106] G. E. McVeigh, D. R. Morgan, P. Allen et al., "Early vascular abnormalities and de novo nitrate tolerance in diabetes mellitus," Diabetes, Obesity and Metabolism, vol. 4, no. 5, pp. 336-341, 2002.

[107] P. Needleman, B. Jakschik, and E. M. Johnson Jr., "Sulfhydryl requirement for relaxation of vascular smooth muscle," Journal of Pharmacology and Experimental Therapeutics, vol. 187, no. 2, pp. 324-331, 1973.

[108] A. Collier, R. Wilson, H. Bradley, J. A. Thomson, and M. Small, "Free radical activity in Type 2 diabetes," Diabetic Medicine, vol. 7, no. 1, pp. 27-30, 1990.

[109] N. Frizzell, M. Rajesh, M. J. Jepson et al., "Succination of thiol groups in adipose tissue proteins in diabetes. Succination inhibits polymerization and secretion of adiponectin," Journal of Biological Chemistry, vol. 284, no. 38, pp. 2577225781, 2009.

[110] A. Seeling and J. Lehmann, "NO-donors, part X[1]: investigations on the stability of pentaerythrityl tetranitrate (PETN) by HPLC-chemoluminescence-N-detection (CLND) versus UV-detection in HPLC," Journal of Pharmaceutical and Biomedical Analysis, vol. 40, no. 5, pp. 1131-1136, 2006.

[111] K. N. Chandrashekar and Muralidhara, "Evidence of oxidative stress and mitochondrial dysfunctions in the testis of prepubertal diabetic rats," International Journal of Impotence Research, vol. 21, no. 3, pp. 198-206, 2009.

[112] E. N. Churchill, M. H. Disatnik, and D. Mochly-Rosen, "Time-dependent and ethanol-induced cardiac protection from ischemia mediated by mitochondrial translocation of eopenPKC and activation of aldehyde dehydrogenase 2," Journal of Molecular and Cellular Cardiology, vol. 46, no. 2, pp. 278-284, 2009.

[113] H. Ma, R. Guo, L. Yu, Y. Zhang, and J. Ren, "Aldehyde dehydrogenase 2 (ALDH2) rescues myocardial ischaemia/ reperfusion injury: role of autophagy paradox and toxic aldehyde," European Heart Journal. In press.

[114] N. Musi, N. Fujii, M. F. Hirshman et al., "AMP-activated protein kinase (AMPK) is activated in muscle of subjects with type 2 diabetes during exercise," Diabetes, vol. 50, no. 5, pp. 921-927, 2001.

[115] S. Wang, J. Xu, P. Song, B. Viollet, and M. H. Zou, "In vivo activation of AMP-activated protein kinase attenuates diabetes-enhanced degradation of GTP cyclohydrolase I," Diabetes, vol. 58, no. 8, pp. 1893-1901, 2009.

[116] E. B. Taylor and L. J. Goodyear, "Targeting skeletal muscle AMP-activated protein kinase to treat type 2 diabetes," Current Diabetes Reports, vol. 7, no. 6, pp. 399-401, 2007.

[117] A. G. Nugent, C. Mcgurk, J. R. Hayes, and G. D. Johnston, "Vascular responses to glyceryl trinitrate and sodium nitroprusside in type 2 diabetes mellitus," British Journal of Clinical Pharmacology, vol. 41, no. 5, pp. 443-444, 1996.

[118] S. Ghio, S. de Servi, R. Perotti, E. Eleuteri, C. Montemartini, and G. Specchia, "Different susceptibility to the development of nitroglycerin tolerance in the arterial and venous circulation in humans: effects of $\mathrm{N}$-acetylcysteine administration," Circulation, vol. 86, no. 3, pp. 798-802, 1992.

[119] D. Fontaine, A. Otto, J. Fontaine, and G. Berkenboom, "Prevention of nitrate tolerance by long-term treatment with statins," Cardiovascular Drugs and Therapy, vol. 17, no. 2, pp. 123-128, 2003. 
[120] H. Watanabe, M. Kakihana, S. Ohtsuka, and Y. Sugishita, "Randomized, double-blind, placebo-controlled study of carvedilol on the prevention of nitrate tolerance in patients with chronic heart failure," Journal of the American College of Cardiology, vol. 32, no. 5, pp. 1194-1200, 1998.

[121] A. Daiber, P. Wenzel, M. Oelze, S. Schuhmacher, T. Jansen, and T. Münzel, "Mitochondrial aldehyde dehydrogenase (ALDH-2)-Maker of and marker for nitrate tolerance in response to nitroglycerin treatment," Chemico-Biological Interactions, vol. 178, no. 1-3, pp. 40-47, 2009.

[122] F. K. Timimi, H. H. Ting, E. A. Haley, M. A. Roddy, P. Ganz, and M. A. Creager, "Vitamin C improves endotheliumdependent vasodilation in patients with insulin-dependent diabetes mellitus," Journal of the American College of Cardiology, vol. 31, no. 3, pp. 552-557, 1998.

[123] H. H. Ting, F. K. Timimi, K. S. Boles, S. J. Creager, P. Ganz, and M. A. Creager, "Vitamin C improves endothelium-dependent vasodilation in patients with noninsulin-dependent diabetes mellitus," Journal of Clinical Investigation, vol. 97, no. 1, pp. 22-28, 1996.

[124] M. S. Bitar, S. Wahid, C. W. T. Pilcher, E. Al-Saleh, and F. Al-Mulla, " $\alpha$-lipoic acid mitigates insulin resistance in GotoKakizaki rats," Hormone and Metabolic Research, vol. 36, no. 8, pp. 542-549, 2004.

[125] L. Zhang, A. Zalewski, Y. Liu et al., "Diabetes-induced oxidative stress and low-grade inflammation in porcine coronary arteries," Circulation, vol. 108, no. 4, pp. 472-478, 2003.

[126] D. Giugliano, R. Marfella, G. Verrazzo et al., "Abnormal rheologic effects of glyceryl trinitrate in patients with noninsulin-dependent diabetes mellitus and reversal by antioxidants," Annals of Internal Medicine, vol. 123, no. 5, pp. 338343, 1995.

[127] P. Wenzel, A. Daiber, M. Oelze et al., "Mechanisms underlying recoupling of eNOS by HMG-CoA reductase inhibition in a rat model of streptozotocin-induced diabetes mellitus," Atherosclerosis, vol. 198, no. 1, pp. 65-76, 2008.

[128] S. Yusuf, K. K. Teo, J. Pogue et al., "Telmisartan, ramipril, or both in patients at high risk for vascular events," New England Journal of Medicine, vol. 358, no. 15, pp. 1547-1559, 2008.

[129] H. Chen, R. J. Karne, G. Hall et al., "High-dose oral vitamin $\mathrm{C}$ partially replenishes vitamin $\mathrm{C}$ levels in patients with Type 2 diabetes and low vitamin $\mathrm{C}$ levels but does not improve endothelial dysfunction or insulin resistance," American Journal of Physiology-Heart and Circulatory Physiology, vol. 290, no. 1, pp. H137-H145, 2006.

[130] D. H. Lee, A. R. Folsom, L. Harnack, B. Halliwell, and D. R. Jacobs Jr., "Does supplemental vitamin C increase cardiovascular disease risk in women with diabetes?" American Journal of Clinical Nutrition, vol. 80, no. 5, pp. 1194-1200, 2004.

[131] R. A. Kowluru, V. Kowluru, Y. Xiong, and Y. S. Ho, "Overexpression of mitochondrial superoxide dismutase in mice protects the retina from diabetes-induced oxidative stress," Free Radical Biology and Medicine, vol. 41, no. 8, pp. 1191-1196, 2006.

[132] M. G. Andreassi, N. Botto, S. Simi et al., "Diabetes and chronic nitrate therapy as co-determinants of somatic DNA damage in patients with coronary artery disease," Journal of Molecular Medicine, vol. 83, no. 4, pp. 279-286, 2005.

[133] A. Warnholtz, H. Mollnau, T. Heitzer et al., "Adverse effects of nitroglycerin treatment on endothelial function, vascular nitrotyrosine levels and cGMP-dependent protein kinase activity in hyperlipidemic Watanabe rabbits," Journal of the
American College of Cardiology, vol. 40, no. 7, pp. 1356-1363, 2002.

[134] A. Hacker, S. Müller, W. Meyer, and G. Kojda, "The nitric oxide donor pentaerythritol tetranitrate can preserve endothelial function in established atherosclerosis," British Journal of Pharmacology, vol. 132, no. 8, pp. 1707-1714, 2001.

[135] S. Oberle, P. Schwartz, A. Abate, and H. Schröder, "The antioxidant defense protein ferritin is a novel and specific target for pentaerithrityl tetranitrate in endothelial cells," Biochemical and Biophysical Research Communications, vol. 261, no. 1, pp. 28-34, 1999.

[136] A. L. Kruger, S. J. Peterson, M. L. Schwartzman et al., "Upregulation of heme oxygenase provides vascular protection in an animal model of diabetes through its antioxidant and antiapoptotic effects," Journal of Pharmacology and Experimental Therapeutics, vol. 319, no. 3, pp. 1144-1152, 2006.

[137] X. Liu, J. Wei, D. H. Peng, M. D. Layne, and S. F. Yet, "Absence of heme oxygenase-1 exacerbates myocardial ischemia/reperfusion injury in diabetic mice," Diabetes, vol. 54, no. 3, pp. 778-784, 2005.

[138] S. Schuhmacher, P. Wenzel, E. Schulz et al., "Pentaerythritol tetranitrate improves angiotensin II-induced vascular dysfunction via induction of heme oxygenase-1," Hypertension, vol. 55, no. 4, pp. 897-904, 2010.

[139] A. Icks, B. Haastert, W. Rathmann, D. Schröder-Bemhardi, and G. Giani, "Cost comparison analysis: pentaerythrithyl tetranitrate (PETN) and isosorbide dinitrate (ISDN) prescribed to diabetic patients in primary care practices in Germany," International Journal of Clinical Pharmacology and Therapeutics, vol. 45, no. 9, pp. 516-523, 2007. 


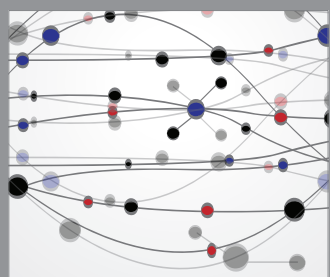

The Scientific World Journal
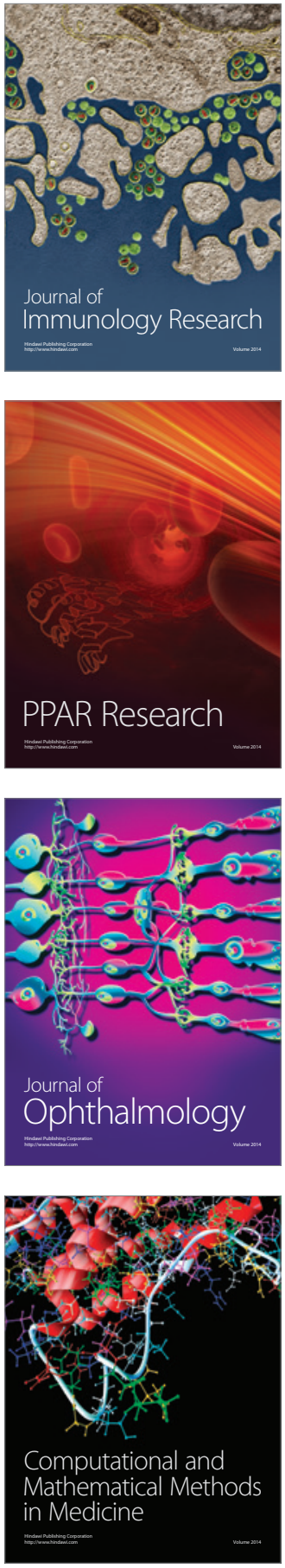

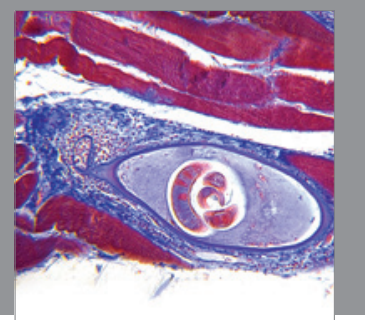

Gastroenterology

Research and Practice
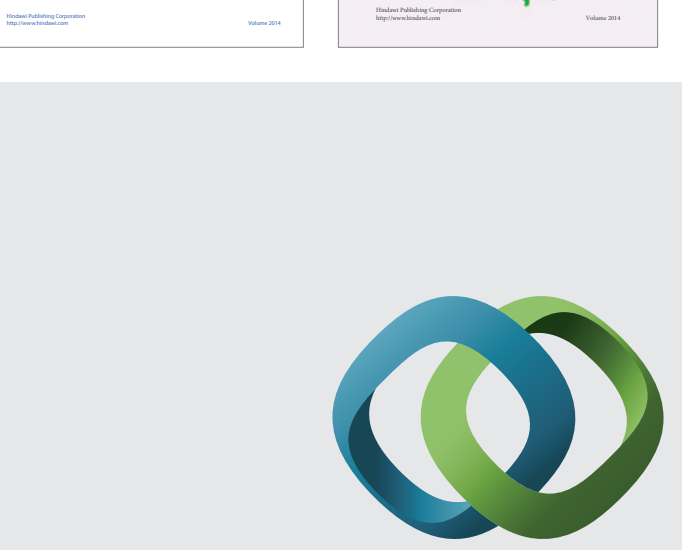

\section{Hindawi}

Submit your manuscripts at

http://www.hindawi.com
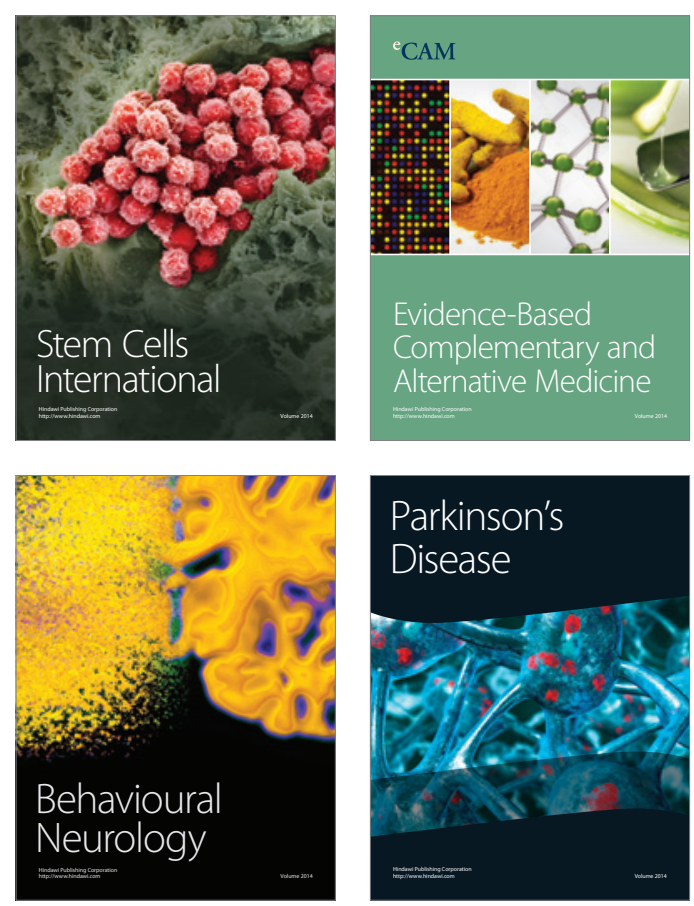

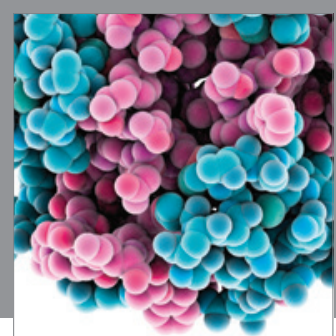

Journal of
Diabetes Research

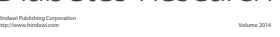

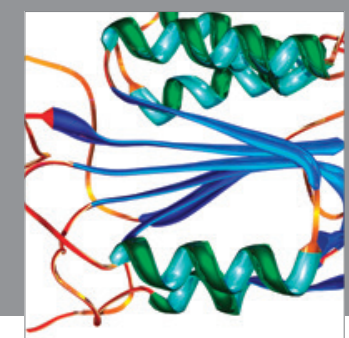

Disease Markers
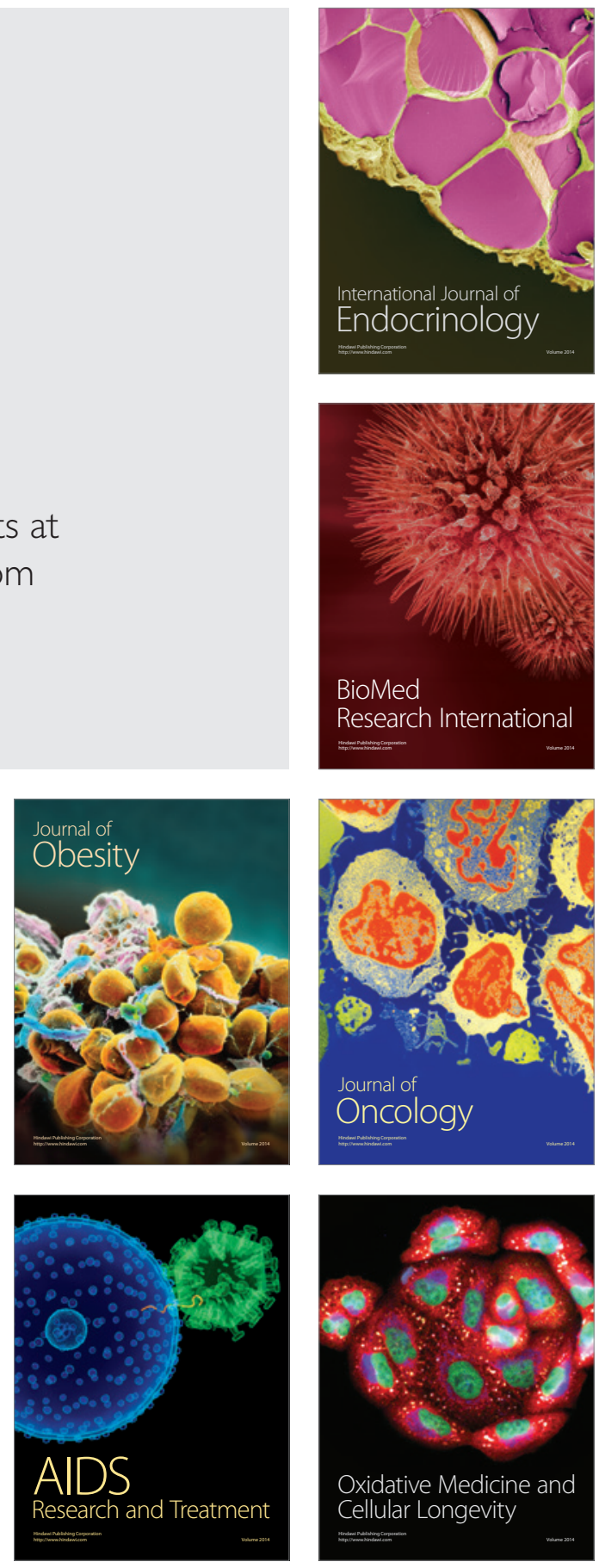